\title{
Brucellosis as the Cause of Pediatric Fever of Unknown Origin
}

\author{
Elda Skenderi, Admir Sulovari, Alberta Shkembi, Nilsa Shahini, Griselda Toci, Ada Pema \\ University Hospital Center "Mother Teresa”, Tirana, Albania \\ Email: elda_skenderi@yahoo.com
}

How to cite this paper: Skenderi, E., Sulovari, A., Shkembi, A., Shahini, N., Toci, G. and Pema, A. (2021) Brucellosis as the Cause of Pediatric Fever of Unknown Origin. Journal of Biosciences and Medicines, 9, 1-7. https://doi.org/10.4236/jbm.2021.912001

Received: October 23, 2021

Accepted: November 27, 2021

Published: November 30, 2021

Copyright $\odot 2021$ by author(s) and Scientific Research Publishing Inc. This work is licensed under the Creative Commons Attribution International License (CC BY 4.0).

http://creativecommons.org/licenses/by/4.0/ (c) (i) Open Access

\begin{abstract}
Brucellosis is the most common zoonotic infection that causes diseases in humans and is continuously a gross public health issue worldwide. Generally, physical examinations are normal or only minimally abnormal and the diagnosis is made on the basis of the history and serologic studies. Disease can be mild and self-limited or fulminant with severe complications. Here is reported a case of a seven years old boy hospitalized for Fever of Unknown Origin. He had no clues on medical history and physical examination. No changes were found on laboratory parameters; normal blood count and normal inflammatory indicators resulted. After a careful investigation, the diagnose of Brucellosis was concluded. Persistent or prolonged fever may be the only presenting symptom in children. The growing phenomena of international tourism and migration have directed interest in Brucellosis as it is increasingly recorded in non-endemic countries.
\end{abstract}

\section{Keywords}

Brucellosis, Fever, Zoonosis, Diagnosis, Children

\section{Introduction}

Brucellosis is the most common zoonotic infections that causes diseases in humans and is continuously a gross public health issue worldwide. The burden of human Brucellosis is estimated to be more than 500,000 infections per year [1]. It is more prevalent in agrarian societies and in countries where handling of animal products and dairy products are less controlled and veterinary measures less efficient. The heaviest disease burden lies in countries of the Mediterranean basin and the Arabian Peninsula.

Brucella organisms localize in the reproductive organs of host animals, causing abortions and sterility and shed in animal's urine, milk, placental and other 
fluids. Of the twelve species identified, four have moderate to significant human pathogenicity: Brucella melitensis (from sheep; highest pathogenicity), Brucella suis (from pigs; high pathogenicity), Brucella abortus (from cattle; moderate pathogenicity), Brucella canis (from dog; moderate pathogenicity) [2] [3].

Brucella are aerobic gram-negative coccobacilli that are capable to invade both phagocytic and non-phagocytic cells and survive in the intracellular environment by generating mechanisms to escape immune system (Figure 1) [4]. Thus this ability makes Brucellosis a systemic disease by involving almost every organsystem [5].

Brucellosis can be transmitted from animals to animals and from animals to humans by direct contact with infected animals or indirect contact with contaminated materials. Brucella enters the human body through breaks in the skin, mucous membranes, conjuctivae, respiratory and gastrointestinal tracts. The most common symptoms are: fever, constitutional symptoms (anorexia, asthenia, fatigue, weakness, asthenia, weight loss), bone and joint symptoms (arthralgias, joint swelling), neurologic symptoms (dizziness, unsteadiness of gait, urinary retention), gastrointestinal symptoms, genitourinary infections [6]. Generally, physical examinations are normal or only minimally abnormal and the diagnosis is made on the basis of the history and serologic studies. Disease can be mild and self-limited or fulminant with severe complications. Usually acute Brucellosis occurs without focal abnormalities. Cultures and serology are necessary for the diagnosis, however serologic testing is the most commonly used method of diagnosis. Prognosis is good and the disease is easily curable with a low risk of relapse or chronic disease when it is appropriately treated within the first few months of onset. However, the prognosis is poor in persons who present with congestive heart failure due to endocarditis in whom mortality approaches $85 \%$.

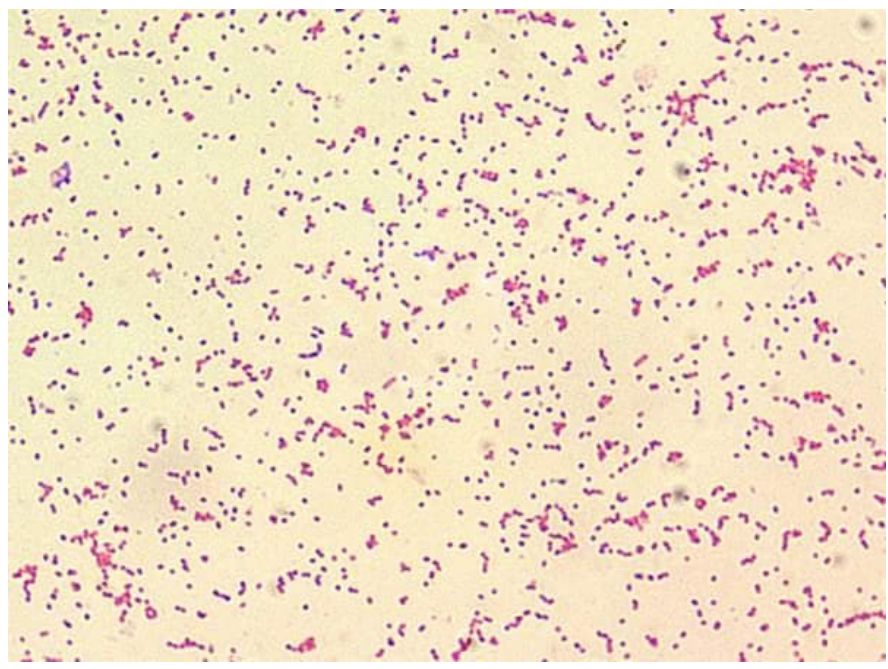

Figure 1. Brucella species are poorly staining, small gram-negative coccobacilli $(0.5-0.7 \times 0.6-1.5 \mu \mathrm{m})$ and are seen mostly as single cells with an appearance resembling "fine sand." [4]. 
Multidrug antimicrobial regimens are the mainstay of therapy because of high relapse rates reported with mono-therapeutic approaches. For Brucellosis in children younger than 8 years, administration of rifampin and TMP-SMZ for 6 weeks is the therapy of choice [7] [8].

\section{Aim}

Brucellosis is still a neglected but not eradicated disease. The aim of this case report is to attract attention over its presentations in children. Brucellosis is a potential cause of pediatric Fever of Unknown Origin.

\section{Case Report}

A 7 years old male B.T. admitted to the University Hospital Center of Tirana with a history of 3 weeks fever. He was treated with oral antibiotics by a local clinic for urinary tract infection but fever persisted in high values $38.5^{\circ} \mathrm{C}-39^{\circ} \mathrm{C}$. The boy lived in a rural area with his family, the parents and a little brother of 7-months old. All the family members were healthy and the boy had been health till then. He was fully vaccinated. The family did not keep domestic animals at home and consumed safe foods.

On physical examination the child did not appear ill, he was play-full despite persistent fever. No weight loss was observed. Sclera were normally, no pharyngeal injection or cervical lymphadenopathy were observed. Pulmonary and cardio-vascular systems were normal, no tachycardia nor tachypnea were observed. The abdomen was soft, not distended, bowel sounds were present, liver and spleen were not palpable. No edema or rash on the skin were observed.

Laboratory investigations on admission revealed a normal blood cell count; WBC 6100 cells $/ \mathrm{mm}^{3}$, 43\% were neutrophils, RBC 5,020,000 cells $/ \mathrm{mm}^{3}$, Hemoglobin level $11.5 \mathrm{~g} / \mathrm{dl}$, Hematocrit value 35.8\%, Platelet count PLT 202,000 cells $/ \mathrm{mm}^{3}$, Erythrocyte sedimentation rate $15 \mathrm{~mm} / \mathrm{h}(<15 \mathrm{~mm} / \mathrm{h})$. Aspartate aminotransferase (AST) $40 \mathrm{U} / \mathrm{L}(0-35 \mathrm{U} / \mathrm{L})$, Alanine aminotransferase (ALT) 35 U/L (0 - 45 U/L), Prothrombin time/ international normalized ratio (INR) 1.14, blood Urea Nitrogen (BUN) $30 \mathrm{mg} / \mathrm{dL}(10-43 \mathrm{mg} / \mathrm{dL})$, Creatinine level 0.5 $\mathrm{mg} / \mathrm{dL}(0.6$ - $1.4 \mathrm{mg} / \mathrm{dL})$, serum Total Protein level $6.8 \mathrm{~g} / \mathrm{dL}(6-8 \mathrm{~g} / \mathrm{dL})$. Albu$\min 4.5 \mathrm{mg} / \mathrm{dL}(3.2-4.5 \mathrm{mg} / \mathrm{dL})$, normal $\mathrm{C}$ reactive protein $0.15 \mathrm{mg} / \mathrm{dL}(<0.5$ $\mathrm{mg} / \mathrm{dL}$ ), normal D-dimer $200 \mathrm{mg} / \mathrm{dL}(<198 \mathrm{mg} / \mathrm{dL})$, Fibrinogen activity 231 $\mathrm{mg} / \mathrm{dL}(160$ - $390 \mathrm{mg} / \mathrm{dL})$, Creatin kinase $75 \mathrm{U} / \mathrm{L}$ (30 - $200 \mathrm{U} / \mathrm{L})$, normal Ferritin value $75 \mathrm{ng} / \mathrm{mL}$ (13.7 - 79.8) (Table 1).

Blood and urine cultures were negative. Radiologic examination of the lungs, heart and abdomen were normal. Laboratory research for Cytomegalovirus (CMV), HIV, Ebstein-Bar virus (EBV), COVID-19 were negative. MANTHOUX reaction test was negative. In the microscopic examination of peripheral blood smear, there were not found abnormal or malignant cells. Rose Bengal test resulted positive and the serum agglutination test (SAT) resulted in values $>1 / 2560$. The diagnosis of Brucellosis was concluded. Therapy with trimethroprim-sulphamethazone (TMP-SMX) and rimfapicin was soon initiated and was continued 
Table 1. Laboratory examinations values.

$\begin{array}{cc}\text { WBC } & 6100 \text { cells/mm } \\ \text { RBC } & 5,020,000 \text { cells } / \mathrm{mm}^{3} \\ \text { Hemoglobin } & 11.5 \mathrm{~g} / \mathrm{dl} \\ \text { PLT } & 202,000 \mathrm{cells} / \mathrm{mm}^{3} \\ \text { ESR } & 15 \mathrm{~mm} / \mathrm{h}(<15 \mathrm{~mm} / \mathrm{h}) \\ \text { INR } & 1.14(0.85-1.15) \\ \text { ALT } & 35 \mathrm{U} / \mathrm{L}(0-45 \mathrm{U} / \mathrm{L}) \\ \text { AST } & 40 \mathrm{U} / \mathrm{L}(0-35 \mathrm{U} / \mathrm{L}) \\ \text { BUN } & 30 \mathrm{mg} / \mathrm{dL}(10-43 \mathrm{mg} / \mathrm{dL}) \\ \text { Creatinin } & 0.5 \mathrm{mg} / \mathrm{dL}(0.6-1.4 \mathrm{mg} / \mathrm{dL}) \\ \text { Total protein } & 6.8 \mathrm{~g} / \mathrm{dL}(6-8 \mathrm{~g} / \mathrm{dL}) \\ \text { Albumin } & 4.5 \mathrm{mg} / \mathrm{dL}(3.2-4.5 \mathrm{mg} / \mathrm{dL}) \\ \text { CRP } & 0.15 \mathrm{mg} / \mathrm{dL}(<0.5 \mathrm{mg} / \mathrm{dL}) \\ \text { D-dimer } & 200 \mathrm{mg} / \mathrm{dL}(<198 \mathrm{mg} / \mathrm{dL}) \\ \text { Fibrinogen } & 231 \mathrm{mg} / \mathrm{dL}(160-390 \mathrm{mg} / \mathrm{dL}) \\ \text { Ferritin } & 75 \mathrm{ng} / \mathrm{mL}(13.7-79.8 \mathrm{ng} / \mathrm{mL}) \\ \text { Creatin kinase } & 75 \mathrm{U} / \mathrm{L}(30-200 \mathrm{U} / \mathrm{L}) \\ \text { Serum Agglutination Test }(\mathrm{SAT}) & >1 / 2560(>1 / 160) \\ & \end{array}$

for 8-weeks. Therapy was well-tolerated by the child. Fever subsided after 2weeks of treatment after that the child dismissed and therapy was continued at home for 6 weeks. SAT values normalized after 8-weeks of treatment.

\section{Discussion}

Fever is one of the oldest clinical feature of disease in humans. It was first described by Celcius around 2000 years ago when he listed the four cardinal features of inflammation: pain, heat, redness and swelling [9]. Almost contemporary Hippocrates noted that fever was of benefit. So from antiquity till now fever is considered to be an adaptive compensatory defense mechanism leading to immune activation, thus improving host survival in response to foreign invasions. In pediatric population fever is the most common reason for medical consultations worldwide, and a found of distress in parents and pediatricians when it is prolonged or persistent.

In 1961 Petersdorf and Beeson defined fever of unknown origin in adults (FUO) as a state of febrile illness for more than three weeks, with a body temperature greater than $38.3^{\circ} \mathrm{C}$ on several occasions and uncertain diagnosis after one week of study in hospital [10]. The definition of FUO in the pediatric group varies, with a time frame ranging from $1-3$ weeks. Even with modern advances in medicine, FUO remains a challenge and it may be a symptom of approximately 
200 described cases. Classical FUO is subdivided in four main etiological categories: infections, malignancies, non-infectious inflammatory diseases and miscellaneous conditions. In children, infections lead the differential diagnosis followed by collagen vascular diseases, malignancy is typically not heralded by fever alone in childhood [11].

Initially the case was very challenging as the child did not appear ill considering the fact that he had high fever for approximately 3 weeks. Furthermore no clues were found in medical history and physical examination. While workup processed with laboratory and radiological examinations; blood count resulted normal, inflammatory indicators ( $\mathrm{C}$ reactive protein, erythrocyte sedimentation ratio, fibrinogen, ferritin) were within the normal range, no organomegaly or lymphadenopathy were found, and no abnormal cells were detected on peripheral blood smear examination.

The fact that no abnormal cells were detected on peripheral blood smear and neither lymphadenopathy nor organomegaly were found on examination made it quite impossible to be in front of a malignant pathology. Furthermore if a non-infectious inflammatory condition was developing any of the inflammatory parameters would have been increased. These facts pointed more towards an infectious disease.

This scenario of no clues found in physical and laboratory examinations, may be very confounding in making a diagnosis but it can be common in childhood Brucellosis. Brucella species have relatively low virulence, toxicity and pyrogenicity, making them poor inducers of some inflammatory cytokines, such as tumor necrosis factor and interferons. Furthermore, the bacteria do not activate the alternative compliment system and the principal mechanism of recovery is the development of cell-mediated immunity. The latency period from infection to onset of symptoms of primary Brucellosis may be as long as months. This fact emphasizes the importance of a meticulous history because often pitfalls are created in making the correct diagnosis. In areas of the world where Brucellosis is rare, the diagnosis may be missed even in patients who manifest typical signs, such as uncomplicated persistent undulating fever. Otherwise the threshold of considering Brucellosis is low in regions of endemic disease, where diagnostic testing is performed for any of the many atypical presentations or unusual complications.

Brucellosis is ranked among the top seven neglected zoonoses by the World Health Organization [12]. In the Mediteranean it has the highest age related incidence in males in their mid-twenties, but a considerable number is found in children too. A report from Saudi Arabia found that $60 \%$ of cases of Brucellosis occurred in individuals aged 13 - 40 years, whereas $21 \%$ occurred in those younger than 13 years [13]. Located in the Mediteranian basin, Albania has been an endemic country since antiquity. An archaeological report assumed that Brucellosis has been endemic in Albania since at least the Middle Ages, DNA sequencing revealed the presence of Brucella IS6501 insertion element in skeletal remains from the ancient city of Butrint [14]. At the beginning of the twentieth 
century the average annual incidence was 23 cases per 100,000. In the following period 1960-1990, the disease was almost eradicated, with only sporadic cases in humans, due to intensive test and slaughter and massive vaccination of animals. During 1991-2004 a comeback of Brucellosis has been documented as a result of political changes and veterinary control failure [15]. From 2005, with the implementation of veterinary programs of mas vaccination of herds, human Brucellosis significantly declined with only sporadic cases recorded in children. Nowadays interest in Brucellosis has been increasing because of the growing phenomena of international tourism and migration.

\section{Conclusion}

Brucellosis is the most common zoonotic infections that causes diseases in humans. Due to the fast development of international tourism and migration, it is recorded even in non-endemic countries worldwide. Symptoms and signs of Brucellosis are protean in nature, and none is specific enough to support the diagnosis. Persistent or prolonged fever may be its only symptom in children. So a high index of suspicion should be kept while evaluating a child with Fever of Unknown Origin.

\section{Acknowledgements}

We thank the medical staff of General Pediatric Ward for the precious support!

The publication was performed on consent of the child's parents providing the anonymity.

\section{Conflicts of Interest}

The authors declare no conflicts of interest regarding the publication of this paper.

\section{References}

[1] Pappas, G., Papadimitriou, P., Akritidis, N., Christou, L. and Tsianos, E.V. (2006) The New Global Map of Human Brucellosis. The Lancet Infectious Diseases, 6, 91-99. https://doi.org/10.1016/S1473-3099(06)70382-6

[2] Rajendhran, J. (2021) Genomic Insights into Brucella. Infection, Genetics and Evolution, 87, Article ID: 104635. https://doi.org/10.1016/j.meegid.2020.104635

[3] El-Sayed, A. and Awad, W. (2018) Brucellosis: Evolution and Expected Comeback. International Journal of Veterinary Science and Medicine, 6, S31-S35. https://doi.org/10.1016/j.ijvsm.2018.01.008

[4] Elham, E. and Bukhari, M.D. (2018) Pediatric Brucellosis. An Update Review for the New Millennium. Saudi Medical Journal, 39, 336-341. https://doi.org/10.15537/smj.2018.4.21896

[5] Lecaroz, C., Blanco-Prieto, M.J., Burrell, M.A., et al. (2006) Intracellular Killing of Brucella melitensis in Human Macrophages with Microsphere-Encapsulated Gentamicin. Journal of Antimicrobial Chemotherapy, 58, 549-556. https://doi.org/10.1093/jac/dkl257

[6] Dean, A.S., Crump, L., Greter, H., Hattendorf, J., Schelling, E. and Zinsstag, J. (2012) 
Clinical Manifestations of Human Brucellosis: A Systematic Review and Meta-Analysis. PLOS Neglected Tropical Diseases, 6, e1929.

https://doi.org/10.1371/journal.pntd.0001929

[7] Lubani, M.M., Dudin, K.I., Sharda, D.C., Ndhar, D.S., Araj, G.F., Hafez, H.A., et al. (1989) A Multicenter Therapeutic Study of 1100 Children with Brucellosis. The Pediatric Infectious Disease Journal, 8, 75-78.

[8] Roushan, M.R., Mohraz, M., Janmohammadi, N. and Hajiahmadi, M. (2006) Efficacy of Cotrimoxazole and Rifampin for 6 or 8 Weeks of Therapy in Childhood Brucellosis. The Pediatric Infectious Disease Journal, 25, 544-545. https://doi.org/10.1097/01.inf.0000219403.91975.ce

[9] Walter, E.J., Jumma, S.H., Carraretto, M. and Forn, L. (2016) The Pathophysiological Basis and Consequences of Fever. Critical Care, 20, 200.

https://www.ncbi.nlm.nih.gov/pmc/articles/PMC4944485

https://doi.org/10.1186/s13054-016-1375-5

[10] Fusco, F.M., Pisapia, R., Nardiello, S., Cicala, S.D., Gaeta, G.B. and Brancaccio, G. (2019) Fever of Unknown Origin (FUO): Which Are the Factors Influencing the Final Diagnosis? A 2005-2015 Systematic Review. BMC Infectious Diseases, 19, 653. https://doi.org/10.1186/s12879-019-4285-8

[11] Finkelstein, J.A., Christiansen, C.L. and Platt, R. (2000) Fever in Pediatric Primary Care: Occurrence, Management, and Outcomes. Pediatrics, 105, 260.

[12] Bundle, D.R. and McGiven, J. (2017) Brucellosis: Improved Diagnostics and Vaccine Insights from Synthetic Glycans. Accounts of Chemical Research, 50, 29582967. https://doi.org/10.1021/acs.accounts.7b00445

[13] Fallatah, S.M., Oduloju, A.J., Al-Dusari, S.N. and Fakunle, Y.M. (2005) Human Brucellosis in Northern Saudi Arabia. Saudi Medical Journal, 26, 1562-1566.

[14] Mutolo, M.J., Jenny, L.L., Buszek, A.R., Fenton, T.W. and Foran, D.R. (2012) Osteological and Molecular Identification of Brucellosis in Ancient Butrint, Albania. American Journal of Physical Anthropology, 147, 254-263. https://doi.org/10.1002/ajpa.21643

[15] Mersini, K., Alla, L., Juma, A., Koleci, X., Crilly, J. and Bino, S. (2019) Review of Brucellosis in Albania: Disease Frequency in Humans and Animals, and One Health Efforts to Control the Disease, 1925 to Present. International Journal of Infectious Diseases, 79, 1-150. https://doi.org/10.1016/j.ijid.2018.11.028 